\title{
Adsorptive removal of cobalt ions on raw and alkali-treated lemon peels
}

\author{
S. A. Singh $^{1} \cdot$ S. R. Shukla ${ }^{1}$
}

Received: 4 December 2014/Revised: 28 January 2015/ Accepted: 15 March 2015/Published online: 9 April 2015

(C) Islamic Azad University (IAU) 2015

\begin{abstract}
Batch-wise biosorption of $\mathrm{Co}$ (II) from aqueous cobalt nitrate solution of different concentrations has been carried out on raw and $\mathrm{NaOH}$-treated lemon peels. They were characterized by Fourier transform infrared spectroscopy, scanning electron microscopy, energy-dispersive $\mathrm{X}$-ray spectroscopy, thermogravimetric analysis and Brunauer-Emmett-Teller surface area analysis. The influence of biosorbent dose, $\mathrm{pH}$, contact time and temperature on the adsorption process has been studied. Maximum adsorption was observed at $\mathrm{pH}$ 6. The equilibrium adsorption on raw and $\mathrm{NaOH}$-treated lemon peels was achieved in 150 and $210 \mathrm{~min}$, the maximum adsorption capacity being 20.83 and $35.71 \mathrm{mg} / \mathrm{g}$, respectively. Energy-dispersive $\mathrm{X}$-ray spectroscopy and desorption study confirmed that the mechanism of adsorption is ion exchange. The Langmuir isotherm and pseudosecond-order kinetic model gave the best fit for the adsorption of $\mathrm{Co}(\mathrm{II})$. The desorption was found to be more than $96 \%$ using $0.1 \mathrm{~N} \mathrm{HCl}$, and the adsorbent could be reused three times with intermediate alkaline regeneration stage. Experiments to establish the effect of competing metal ions on biosorption capacity were also performed. Thus, $\mathrm{NaOH}$-treated lemon peels have shown the potential as a good biosorbent for treating industrial wastewater at low cobalt concentration.
\end{abstract}

Electronic supplementary material The online version of this article (doi:10.1007/s13762-015-0801-6) contains supplementary material, which is available to authorized users.

\section{S. R. Shukla}

srshukla19@gmail.com

1 Department of Fibres and Textile Processing Technology, Institute of Chemical Technology, Matunga, Mumbai 400019, India
Keywords Biosorption - Cobalt(II) · Langmuir · Pseudosecond order · Synthetic wastewater

\section{Introduction}

The release of metal salts into effluents is exceptionally detrimental to the living organisms. Metal ions pass through the food chain and ultimately get bioaccumulated in the body of living beings. These are nonbiodegradable and many times toxic, and hence, their removal is essential (Hlihor et al. 2013).

Cobalt is one of the most important strategic metals because of its use in the production of super alloys, permanent magnets, lithium ion batteries, electronic devices and many modern warfare systems. Cobalt is used in electroplating, metallurgical, mining, paint and petrochemical industry and present in the wastewater of nuclear power plants (Suhasini et al. 1999; Manohar et al. 2006).

Cobalt as a contaminant has many ill effects on human health such as imparting bronchial asthma, cardiomyopathy and neurotoxicological disorders such as headaches and changes in reflexes, nausea and vomiting. Continuous exposure to cobalt results in paralysis, diarrhea, low blood pressure, lung irritation, bone defects and even cancer (Awadalla and Pesic 1992; Parab et al. 2006; Ahmadpour et al. 2009). The permissible limit of cobalt in wastewater from industry is $1.0 \mathrm{mg} / \mathrm{L}$, and in potable water, it is $0.05 \mathrm{mg} / \mathrm{L}$ (Manohar et al. 2006; the environmental management (water quality standards) regulations 2007.

Biosorption is defined as a metabolically independent process in which passive uptake of metal ions takes place from an aqueous solution. Conventional treatment techniques used for metal removal are either expensive or inefficient, especially when the heavy metal concentration is 
below $100 \mathrm{mg} / \mathrm{L}$. Activated carbon produced from agricultural and industrial wastes has been used efficiently for metal removal; however, the cost and regeneration is the major concern. As a solution to all these problems, biosorption is an advantageous technique for the industry and the society (O'Connell et al. 2008; Ekmekyapar et al. 2012; Ileri et al. 2014; Rouhollahi et al. 2014).

Literature survey has shown that the various adsorbents experimented so far for cobalt removal are Al-pillared bentonite clay (Manohar et al. 2006), $\mathrm{AMT}^{\mathrm{TM}}$ metal removing agent (Awadalla and Pesic 1992), Kaolinite (Yavuz et al. 2003), PFB1 (fungal-based biosorbent) (Suhasini et al. 1999), pretreated arca green hull (Dahiya et al. 2008), almond green hull (Ahmadpour et al. 2009), Coir pith (Parab et al. 2006), Schizandra chinesis fruit peel (Koduru et al. 2014) and Saccharum bengalense (Din et al. 2013).

Earlier work on coir, jute, sawdust, groundnut shells and citrus limmeta peels both in their raw and modified forms has shown their potential to adsorb $\mathrm{Pb}$ (II) (Pai and Shukla 2005a; Suryavanshi and Shukla 2010), Ni(II), Zn(II), Fe(II) and $\mathrm{Cu}$ (II) (Pai and Shukla 2005b; Shukla and Shukla 2013) ions from their aqueous solutions.

Lemon peels were selected as they contain polysaccharides such as pectin $(33.87 \%)$ and cellulose $(14.35 \%)$, which are rich in functional groups such as carboxylic (in galacturonic acids) and hydroxyl (in cellulose) as compared to other citrus fruit peels and known to bind divalent cations (Thirumavalavan et al. 2010; Thirumavalavan et al. 2011). Apart from the richness of functional groups, physical stability, low cost and easy availability of lemon peels were the additional factors considered for the selection.

In the present work, raw lemon peels were treated with different chemicals and checked for their adsorptive capacity to remove $\mathrm{Co}$ (II) from aqueous solution.

This work was conducted at the Department of Fibres and Textile Processing Technology, Institute of Chemical Technology, Matunga, Mumbai, 400019, India, between January, 2014, and November, 2014.

\section{Materials and methods}

\section{Preparation of the biosorbent}

The lemon peels were collected from the local fruit market, washed thoroughly with water to remove dust and dried for $24 \mathrm{~h}$ in an oven at $60{ }^{\circ} \mathrm{C}$. The peels were crushed in a domestic mixer, washed again with demineralized water until colorless filtrate was obtained and then dried in an oven for $24 \mathrm{~h}$ at $60{ }^{\circ} \mathrm{C}$ and sieved to approximately $1 \mathrm{~mm}$ size. These are called as raw lemon peels (RLP).

\section{Pretreatment of biosorbent}

The RLP particles (approximately $10 \mathrm{~g}$ ) were slowly agitated with $100 \mathrm{~mL}$ of different agents (20\% iso-propanol, $0.1 \mathrm{~N} \mathrm{NaOH}, 0.1 \mathrm{~N} \mathrm{HCl}, 0.1 \mathrm{~N} \mathrm{H}_{2} \mathrm{SO}_{4}, 0.1 \mathrm{~N}$ $\mathrm{HNO}_{3}, 50 \% \mathrm{H}_{2} \mathrm{O}_{2}$ ) for $4 \mathrm{~h}$ at $30{ }^{\circ} \mathrm{C}$ to check the enhancement in the adsorption capacity and biomass loss, if any. After each treatment, the RLP particles were washed with demineralized water till neutral $\mathrm{pH}$, dried in an oven at $60{ }^{\circ} \mathrm{C}$ for $24 \mathrm{~h}$ and weighed to estimate the biomass loss (S 1). All the chemicals used were of analytical reagent grade. The peels treated with $\mathrm{NaOH}$ were called as alkalitreated lemon peels (ALP). Biomass loss during pretreatment was estimated gravimetrically.

\section{Determination of the point of zero charge}

The point of zero charge (PZC) for the lemon peels was determined by the method reported by Leyva-Ramos et al. (2005). Deionized water (100 mL), taken in an Erlenmeyer flask, was boiled for $20 \mathrm{~min}$ to remove $\mathrm{CO}_{2}$ dissolved in the water. The $\mathrm{CO}_{2}$ free water was quickly cooled, and the flask was immediately capped. This water is considered to be neutral. The adsorbent $(0.5 \mathrm{~g})$ was placed in a $25-\mathrm{mL}$ Erlenmeyer flask to which $10 \mathrm{~mL}$ of $\mathrm{CO}_{2}$ free deionized water was added. The flask was sealed with a rubber stopper and agitated for $48 \mathrm{~h}$ at $25^{\circ} \mathrm{C}$. The $\mathrm{pH}$ of the solution measured after this duration was the PZC.

\section{Preparation of metal ion solution}

A stock solution of about $1000 \mathrm{mg} / \mathrm{L}$ concentration of $\mathrm{Co}$ (II) was prepared by dissolving cobalt nitrate (Thomas Baker) in demineralized water. All the required metal concentrations were prepared by diluting the stock solution with demineralized water. Standard solution $(1000 \mathrm{mg} / \mathrm{L})$ of $\mathrm{Co}$ (II) for atomic absorption spectrometer (AAS) was supplied by Merck (I) Ltd. Analytical grade sodium hydroxide, hydrochloric acid and iso-propanol were supplied by SD Fine Chemicals (India) Ltd. Demineralized water was used to carry out all the experiments.

\section{Biomass characterization}

Scanning electron microscope (SEM) (JEOL JSM 6380LA, Japan) was used to study differences in surface morphology of lemon peels before and after the alkali treatment $(0.1 \mathrm{~N}$ $\mathrm{NaOH}, 30^{\circ} \mathrm{C}, 4 \mathrm{~h}$ ). In order to prevent charging, the samples were coated with a thin layer of gold using a sputter coater and examined under the SEM at $20 \mathrm{kV}$ with an angle of $45^{\circ}$. The distance of sample from the sample probe was $10 \mathrm{~mm}$. 
The attenuated total reflectance (ATR) spectra of RLP, ALP and metal-loaded alkali lemon peels (MALP) were recorded with Shimadzu 8400S Fourier transform infrared (FTIR) spectrometer to determine the possible conversion of the functional groups. Fifty scans were recorded on each sample on ATR sampling unit with a resolution of $2 \mathrm{~cm}^{-1}$.

Surface area measurement, pore size and pore volume distribution analysis of RLP and ALP were carried out by nitrogen adsorption-desorption method on Micromeritics ASAP 2010 instrument at a degas temperature of $50^{\circ} \mathrm{C}$ after the sample was kept under high vacuum at $-198{ }^{\circ} \mathrm{C}$ for $4 \mathrm{~h}$ to remove moisture and volatile components.

Thermogravimetric analysis (TGA) was carried out on Shimadzu model DTG-60H operated under nitrogen atmosphere at a heating rate of $10{ }^{\circ} \mathrm{C} / \mathrm{min}$ from 33 to $500{ }^{\circ} \mathrm{C}$.

\section{Determination of accessibility by iso-propanol retention}

RLP and ALP accessibility was determined by iso-propanol retention method, based on displacement of water absorbed by the peels with iso-propanol without swelling of the material and removal of extraneous liquid by centrifuging. The experimental procedure has been reported earlier (Pai and Shukla 2005b).

\section{Batch-wise adsorption studies}

The batch-wise adsorption was carried out at room temperature $\left(30^{\circ} \mathrm{C}\right)$ to study the influence of different parameters on the biosorption process. Unless otherwise specified, all the studies were carried out with $0.1 \mathrm{~g}$ of RLP and ALP biomass mixed with $50 \mathrm{~mL}$ of $\mathrm{Co}(\mathrm{II})$ solution $(100 \mathrm{mg} / \mathrm{L})$. Thus, $0.1 \mathrm{~g}$ of biosorbent was immersed in $50 \mathrm{~mL}$ of metal ion solution of varying initial concentrations ranging from 25 to $600 \mathrm{mg} / \mathrm{L}$ in a $100-\mathrm{mL}$ Erlenmeyer flask and kept for agitation on an orbital shaker (Rossari Biotech Ltd, Mumbai) at a constant speed of $150 \mathrm{rpm}$ for $6 \mathrm{~h}$. It was then filtered with Whatman filter paper no. 42, diluted to appropriate concentration, few drops of $0.1 \mathrm{~N} \mathrm{HCl}$ added, and the left over $\mathrm{Co}(\mathrm{II})$ was estimated on atomic absorption spectrometer (AAS) (model GBC 932 plus, Australia) with an air-acetylene flame at a wavelength of $240.7 \mathrm{~nm}$ and slit width of $0.2 \mathrm{~nm}$. The quantity of metal adsorbed at equilibrium was calculated by the following expression:

$q_{\mathrm{e}}=\frac{\left(C_{\mathrm{i}}-C_{\mathrm{e}}\right) V}{m}$

where $q_{\mathrm{e}}$ is the equilibrium adsorption capacity $(\mathrm{mg} / \mathrm{g}), C_{\mathrm{i}}$ and $C_{\mathrm{e}}$ are the initial and equilibrium metal ion concentrations $(\mathrm{mg} / \mathrm{L})$, respectively, $V$ is the volume of the solution (L), and $m$ is the mass of adsorbent $(\mathrm{g})$.
"A" grade apparatus was used for all the experiments. Experiments were performed in triplicate and mean value reported. No metal ion adsorption takes place on the walls of the glass apparatus used.

\section{Effect of RLP pretreatment on metal removal}

The influence of pretreatments on the RLP adsorption capacity was evaluated by agitating about $0.1 \mathrm{~g}$ of the pretreated sample with $50 \mathrm{~mL}$ of $\mathrm{Co}(\mathrm{II})$ solution $(100 \mathrm{mg} / \mathrm{L})$ in an Erlenmeyer flask kept at $30{ }^{\circ} \mathrm{C}$ on an orbital shaker machine at $150 \mathrm{rpm}$ for $6 \mathrm{~h}$. The solution obtained after filtering the suspension through Whatman filter paper no. 42 was acidified with $0.1 \mathrm{~N} \mathrm{HCl}$, and the Co(II) concentration was determined using AAS.

\section{Kinetic study}

The kinetics was carried out by stirring $0.4 \mathrm{~g}$ of biosorbent in $200 \mathrm{~mL}$ of $100 \mathrm{mg} / \mathrm{L}$ cobalt ion solution maintained at an optimum $\mathrm{pH}$ of 6 in a $250-\mathrm{mL}$ of Erlenmeyer flask at room temperature $\left(30^{\circ} \mathrm{C}\right)$. The stirring was continued up to $300 \mathrm{~min}$, solution was withdrawn at predetermined time interval by a syringe, filtered, and the Co(II) ion concentration in the filtrate was estimated.

\section{Adsorption isotherm}

The linearized form of the Langmuir equation is:

$\frac{C_{\mathrm{e}}}{q_{\mathrm{e}}}=\frac{1}{q_{\max } b}+\frac{C_{\mathrm{e}}}{q_{\max }}$

where $q_{\mathrm{e}}$ is the equilibrium metal ion uptake $(\mathrm{mg} / \mathrm{g}), q_{\max }$ represents the maximum uptake of metal ion $(\mathrm{mg} / \mathrm{g}), b$ is a constant related to the energy of adsorption $(\mathrm{L} / \mathrm{mg})$, and $C_{\mathrm{e}}$ is the equilibrium concentration of the metal ion in solution (mg/L) (Langmuir 1918).

$q_{\text {max }}$ and $b$ can be determined from the linear plot of $C_{\mathrm{e}} /$ $q_{\mathrm{e}}$ versus $C_{\mathrm{e}}$.

$R_{\mathrm{L}}$, referred to as separation factor or equilibrium factor, provides information about spontaneity of the adsorption process. It is given by the following equation:

$R_{L}=\frac{1}{1+b C_{\mathrm{i}}}$

where $b$ is the Langmuir constant and $C_{\mathrm{i}}$ is the initial Co(II) ions concentration in $\mathrm{mg} / \mathrm{L}$. The adsorption process is favorable if $0<R_{\mathrm{L}}<1$ (Singh et al. 2014).

The linearized Freundlich equation in logarithmic form is given (Freundlich 1906) as

$\log q_{\mathrm{e}}=K_{\mathrm{f}}+\left(\frac{1}{n}\right) \log C_{\mathrm{e}}$ 
where $K_{\mathrm{f}}$ is adsorption capacity and $n$ is a dimensionless component related to the energy of adsorption, i.e., adsorption intensity.

$K_{\mathrm{f}}$ and $(1 / n)$ can be determined by plotting $\log q_{\mathrm{e}}$ versus $\log C_{\mathrm{e}}$.

Sips is a three parameter isotherm which is the combination of both Langmuir and Freundlich isotherm applicable for explaining heterogeneous adsorption system.

It has the following form (Sips 1948)

$q_{\mathrm{eq}}=\frac{k_{\mathrm{s}} C_{\mathrm{eq}}^{n_{\mathrm{s}}}}{1+a_{\mathrm{s}} k_{\mathrm{s}} C_{\mathrm{eq}}^{n_{\mathrm{s}}}}$

where $k_{\mathrm{s}}$ is the Sips model isotherm constant $(\mathrm{L} / \mathrm{g}), a_{\mathrm{s}}$ is the Sips model constant $(\mathrm{L} / \mathrm{mg})$, and $n_{\mathrm{s}}$ is the Sips model exponent. At low metal concentration, it reduces to Freundlich isotherm and thus does not obey Henry's law. At high concentration, it gives monolayer formation which results into a Langmuir isotherm with distinctive feature of $n_{\mathrm{s}}$, i.e., the Sips model exponent.

\section{Adsorption kinetics}

The linearized version of pseudofirst-order model is obtained as follows (Lagergren 1898):

$\log \left(q_{\mathrm{e}}-q_{\mathrm{t}}\right)=\log q_{\mathrm{e}}-\left(\frac{K_{1}}{2.303}\right) t$.

The plot of $\log \left(q_{\mathrm{e}}-q_{t}\right)$ versus $t$ gives the rate constant and $q_{\mathrm{e}}$ from the slope and the intercept, respectively.

The pseudosecond-order reaction kinetics is expressed as follows (Ho and Wang 2004)

$\frac{\mathrm{d} q}{\mathrm{~d} t}=K_{2}\left(q_{\mathrm{e}}-q_{t}\right)^{2}$

where $K_{2}$ is the rate constant of pseudosecond-order adsorption (g/mg min). Applying boundary conditions, $t=0$ to $t$ and $q_{t}=0$ to $q_{t}$, the integrated and linearized form of the equation becomes:

$\frac{t}{q_{t}}=\frac{1}{K_{2} q_{\mathrm{e}}^{2}}+\frac{t}{q_{\mathrm{e}}}$.

If the initial adsorption rate $h(\mathrm{mg} / \mathrm{g} \mathrm{min})$ is given by

$h=K_{2} q_{\mathrm{e}}^{2}$

then it changes to

$\frac{t}{q_{t}}=\frac{1}{h}+\frac{t}{q_{\mathrm{e}}}$.

The pseudosecond-order plot is developed by plotting $\frac{t}{q_{t}}$ versus $t$. The values of $q_{\mathrm{e}}$ and $K_{2}$ may be calculated from the slope and the intercept, respectively.
Intraparticle diffusion model proposed by Weber and Morris (Weber and Morris 1963) is given by

$q_{t}=k_{\mathrm{i}} t^{1 / 2}+c$

where $q_{t}(\mathrm{mg} / \mathrm{g})$ is the metal ion adsorbed at time $t, k_{\mathrm{i}}(\mathrm{mg} /$ $\left.\mathrm{g} \mathrm{h}^{1 / 2}\right)$ is the intraparticle diffusion rate constant, and $c(\mathrm{mg} / \mathrm{g})$ is intercept linked to the boundary layer thickness. The plot of $q_{t}$ as a function of square root of time gives the value of $k_{i}$. Straight line plot passing through the origin indicates that the adsorption follows intraparticle diffusion kinetics.

\section{Effect of competing cations and anions}

In order to study the effect of various competing ions on Co(II) adsorption, ALP experiments were performed by adding 50 and $100 \mathrm{mg} / \mathrm{L}$ solutions of interfering ions $\left(\mathrm{Na}^{+}\right.$, $\mathrm{K}^{+}, \mathrm{Ca}^{2+}, \mathrm{Mg}^{2+}$ and $\mathrm{Cl}^{-}, \mathrm{NO}^{3-}, \mathrm{SO}_{4}{ }^{2-}$ ) to $50 \mathrm{~mL}$ of $100 \mathrm{mg} / \mathrm{L} \mathrm{Co}(\mathrm{II})$ solution containing $0.1 \mathrm{~g}$ of biosorbent maintained at $\mathrm{pH} 6$ and room temperature $\left(30{ }^{\circ} \mathrm{C}\right)$. The residual $\mathrm{Co}(\mathrm{II})$ concentration in solution was analyzed by AAS.

\section{Desorption and regeneration}

The desorption of metal ions from metal-loaded RLP and ALP was achieved by agitating the metal-loaded adsorbent $(0.4 \mathrm{~g})$ on an orbital shaker with $50 \mathrm{~mL}$ of $0.1 \mathrm{~N} \mathrm{HCl}$ at room temperature in $100-\mathrm{mL}$ Erlenmeyer flask. The amount of metal ions desorbed in acid solution was determined by AAS. All of the experiments were repeated thrice and the average values reported.

The desorption efficiency was calculated by,

Desorption $(\%)=\frac{q_{\mathrm{d}}}{q_{\mathrm{a}}} \times 100$

where $q_{\mathrm{d}}$ is the amount of metal ion desorbed $(\mathrm{mg} / \mathrm{L})$ and $q_{\mathrm{a}}$ is the amount of metal ion adsorbed $(\mathrm{mg} / \mathrm{L})$.

After desorption, the biosorbents were washed thoroughly with demineralized water and agitated with $50 \mathrm{~mL}$ of $0.01 \mathrm{~N} \mathrm{NaOH}$ for 60 min on an orbital shaker at room temperature $\left(30^{\circ} \mathrm{C}\right)$ for regeneration, washed with demineralized water till neutral $\mathrm{pH}$, dried in an oven and then reused for adsorption study. The experiment was also performed without treatment with $\mathrm{NaOH}$. Three cycles of adsorption-desorption were carried out.

Preparation of synthetic wastewater

Synthetic wastewater randomly containing $30 \mathrm{mg} / \mathrm{L}$ $\mathrm{Co}$ (II) along with the addition of another heavy metal $(\mathrm{Pb}(\mathrm{II}), 5 \mathrm{mg} / \mathrm{L})$ ) and an organic pollutant (phenol, $5 \mathrm{mg} /$ L) was prepared and subjected to adsorption on a column loaded with ALP. 


\section{Statistical analysis}

To establish the model fit, mean squared errors (MSE) were calculated as follows:

$\mathrm{MSE}=\frac{\sum_{1}^{p}\left(q-q_{m}\right)^{2}}{p}$

where $q$ is the experimental metal uptake data, $q_{m}$ is the corresponding model prediction of the uptake, and $p$ is the number of data points for each set.

\section{Results and discussion}

\section{Effect of pretreatment}

Pretreatment removes surface impurities and exposes more active binding sites on the surface of the biosorbent. The importance of cellulose, hemicelluloses and lignin in heavy metal biosorption has been well established, which is mainly attributed to the presence of carboxylic and hydroxyl groups (Suryavanshi and Shukla 2010; Thirumavalavan et al. 2010). RLP was treated with different chemicals (S 1). Out of these, iso-propanol is responsible for eliminating some soluble components without affecting the nature and amount of metal binding sites present in the biomass. Acids used for the pretreatment may dissolve the cell walls of the biomass, thus resulting into opening up of the physical structure to enhance the number of binding sites available. Oxidative pretreatment also has been shown to increase the adsorption capacity of cellulosic biomass such as jute and coir (Pai and Shukla 2005b; Suryavanshi and Shukla 2009).

Biomass loss was observed during the pretreatments of RLP. The maximum weight loss of $19.4 \%$ was recorded when RLP was treated with $0.1 \mathrm{~N} \mathrm{HCl}$, whereas the minimum weight loss of $5.1 \%$ was observed when the treatment was with $20 \%$ iso-propanol.

Batch experiments were performed on the sorption of Co(II) with untreated as well as variously treated RLP, and comparative adsorption capacities are presented in S 1 . The increase in adsorption capacity $(25.43 \mathrm{mg} / \mathrm{g})$ was found to be maximum only in case of alkali $\left(0.1 \mathrm{~N} \mathrm{NaOH}, 30{ }^{\circ} \mathrm{C}\right.$, $4 \mathrm{~h}$ ) treatment with a biomass loss of $14.7 \%$ during the pretreatment. This alkali-treated biomass was designated ALP.

Among all the given treatments, alkali treatment was therefore adopted as it is a cheap, environment friendly treatment, which showed maximum adsorption capacity.
The treatment results in change in the surface morphology and crystallinity of RLP, causes removal of organic substances and modifies/exposes more functional groups. Also, the protonation of carboxylate groups of the pectin molecules is prevented, which restricts the formation of hydrogen bonds, a condition that is favorable for hydration. The carboxylic groups on the surface of the cell wall are exposed, and the $\mathrm{H}^{+}$type of functional groups get converted into the $\mathrm{Na}^{+}$type, which help in preferential ion exchange, so that $\mathrm{Co}(\mathrm{II})$ ions can be bound more easily (Pai and Shukla 2005b; Suryavanshi and Shukla 2010).

Biosorbent selection for industrial application mainly depends on the economic perspective. Hence, it is important to measure the biomass loss caused by a treatment in conjunction with the quantitative biosorption performance, since enhancement in the adsorption capacity may be offset to some extent due to the biomass loss. A detailed analysis of the price of the chemicals, biomass loss after the pretreatment and the assessment of adsorption capacity resulted in the selection of ALP, which was obtained by the pretreatment of RLP with $0.1 \mathrm{~N} \mathrm{NaOH}$ at $30{ }^{\circ} \mathrm{C}$ for $4 \mathrm{~h}$.

\section{Biosorbent characterization}

The SEM images of RLP (Fig. 1a) and ALP (Fig. 1b) showed the presence of pores and cavities on the surface. The alkali treatment changed the morphology and texture of ALP making the grooves and fissures more clearly visible. Alkali treatment led to opening of the pores. The increased surface area of ALP is attributed to the enhancement in porosity, exposing more functional groups for adsorption. Figure 1c shows that in the case of MALP; the pores mostly get covered and/or disappear.

Thirumavalavan et al. (2010) have reported that ALP possesses higher amount of carboxyl groups as a result of saponification of protein and other organic matter but decreased amounts of phenolic and lactone contents in comparison with RLP. The broad and strong peak of absorption observed in the range of $3600-2500 \mathrm{~cm}^{-1}$ is because of $\mathrm{O}-\mathrm{H}$ stretching vibration due to inter- and intramolecular hydrogen bonding of polymeric compounds (macromolecular associations) such as alcohols, phenols and carboxylic acids present in pectin, cellulose and lignin. The peak at $1726 \mathrm{~cm}^{-1}$ in case of RLP is due to ester carbonyl $(\mathrm{C}=\mathrm{O})$ group which has disappeared in ALP due to hydrolysis of this group into carboxyl group. Same was the observation in case of MALP. The peak around $1612 \mathrm{~cm}^{-1}$ is due to carboxylate ion $\left(\mathrm{COO}^{-}\right)$stretching vibration (Fig. 2). No shifts in major IR bands were 

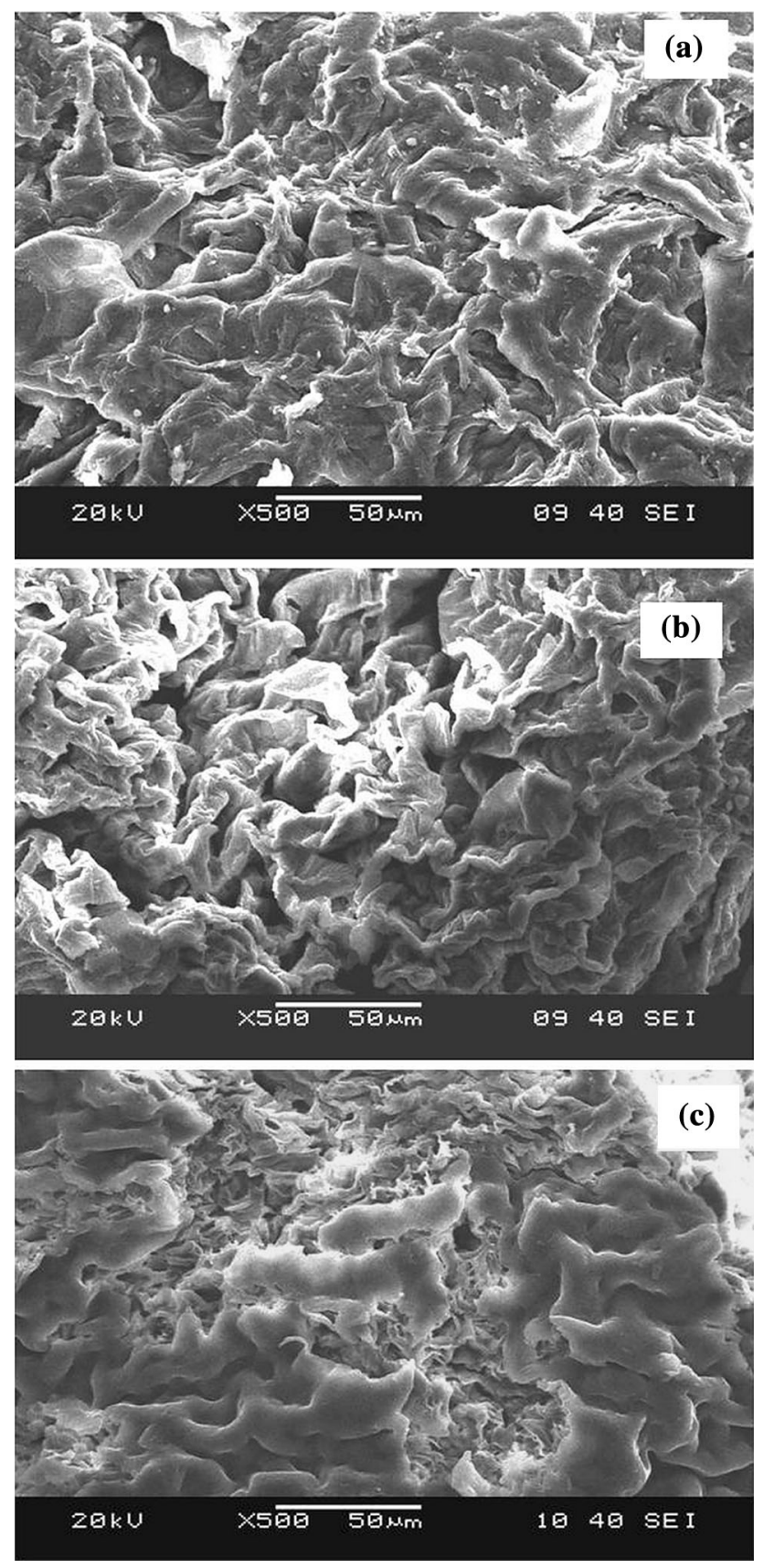

Fig. 1 SEM micrographs of a RLP, b ALP, c MALP

observed. Similar results have been reported by other researchers (Thirumavalavan et al. 2010; Thirumavalavan et al. 2011).

The surface area of the adsorbent plays very important role in the adsorption process. From $\mathrm{S} 2$, it may be observed that alkali treatment caused an increase in the Brunauer-Emmett-Teller (BET) surface area, adsorption average pore width as well as in the total volume in pores. The $\%$ increase in BET surface area for ALP as compared to RLP is $78.02 \%$. The increased adsorption capacity of ALP is attributed to enhanced internal surface area, which is clear from the BET analysis and SEM image.

Thermal stability of the biosorbent is an important parameter to check the applicability of biosorbent in industry. It may be checked by calculating total weight loss of RLP and ALP during TGA analysis. The biosorbents, when heated from 33 to $500{ }^{\circ} \mathrm{C}$, showed three distinct steps of decomposition. In the first step, from 33 to $150{ }^{\circ} \mathrm{C}$, around $10 \%$ weight loss was observed for both RLP and ALP due to loss of moisture. The maximum weight loss occurred during the next step $\left(150\right.$ to $\left.300{ }^{\circ} \mathrm{C}\right)$ caused by the decomposition of all cellulosic matter at around $300{ }^{\circ} \mathrm{C}$. More thermally stable components, such as lignin, decompose at around $400{ }^{\circ} \mathrm{C}$ during the third step of heating in the range of $300-500{ }^{\circ} \mathrm{C}$ (S 3) (Sharma et al. 2004). Total weight loss in case of RLP and ALP is 71.89 and $66.79 \%$, respectively, indicating that ALP is thermally more stable as compared to RLP (S 2).

\section{Iso-propanol retention}

It is a recognized technique to evaluate the increase in accessibility of a cellulosic material caused due to any inter crystalline swelling agent, which ruptures the inter-chain hydrogen bonds (Andrews and Oberg 1963). The technique, therefore, offers better understanding about the accessible structure of the adsorbent more or less in a comparative manner to estimate the effect exerted on openness of cellulosic structure caused by any modification. Apart from the chemical nature of the adsorbing material, the openness or accessibility of its physical structure also plays a crucial role in allowing metal ions to be adsorbed on the external as well as internal crystallite surfaces of the material. The \% increase in iso-propanol retention for ALP as compared to RLP is $69.73 \%$ (S 2). The results are in agreement with SEM and BET, explaining the higher adsorption capacity of ALP.

\section{Effect of pH}

The solution $\mathrm{pH}$ is of utmost importance in metal ion adsorption studies, as it plays a vital role in speciation of metal ions in solution, and also in determining the ionization state of different functional groups on the biosorbent surface. Cobalt is primarily present as $\mathrm{Co}(\mathrm{II})$ cation in broad $\mathrm{pH}$ range from 2.0 to 7.5 . The concentration of 
Fig. 2 FTIR spectra of RLP, ALP and MALP biomass

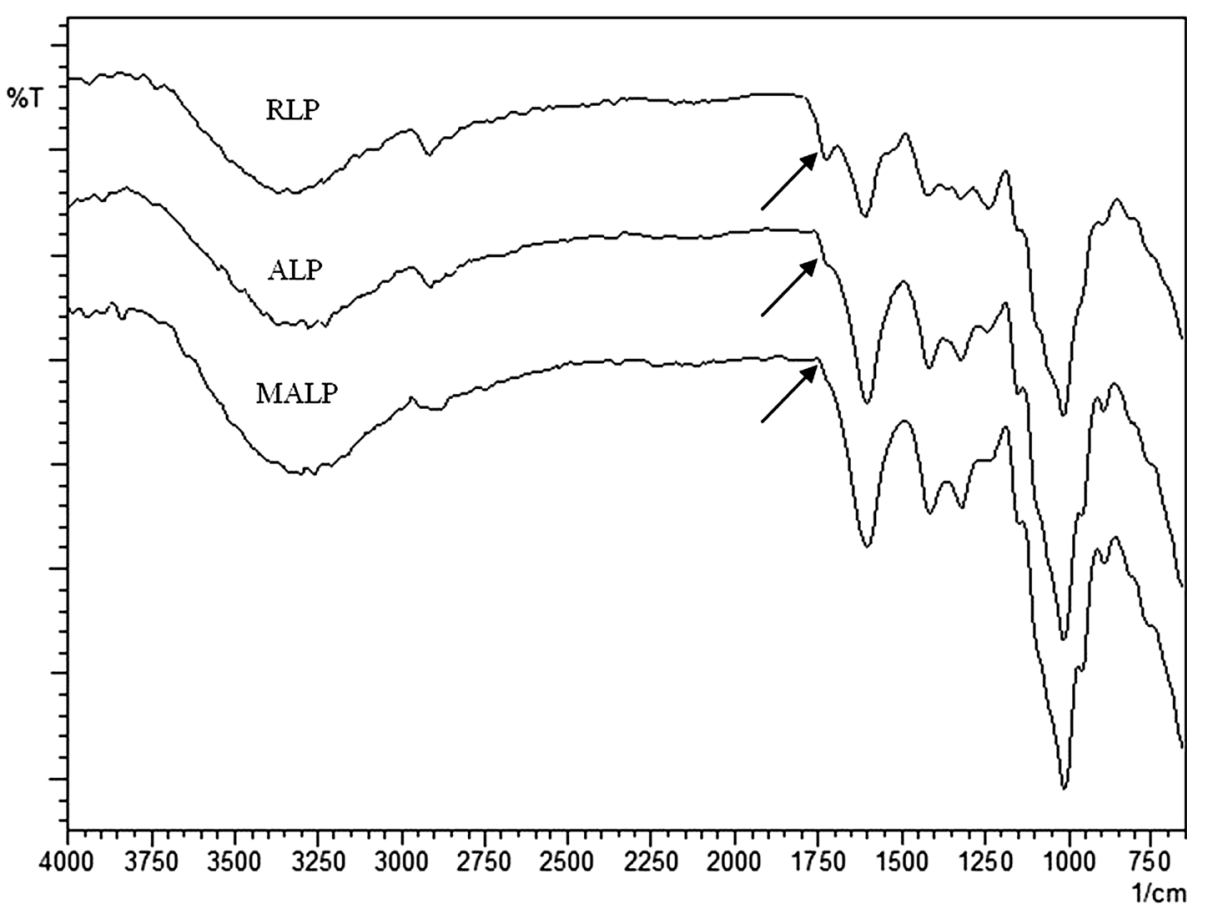

$\mathrm{Co}$ (II) begins to decline at $\mathrm{pH}$ 8.0. Ionic forms $\left(\mathrm{CoCl}^{+}\right.$, $\left.\mathrm{CoOH}^{+}, \mathrm{Co}_{4}(\mathrm{OH})_{4}^{4+}, \mathrm{Co}(\mathrm{OH})_{3}^{-}\right)$are present in considerable amounts in solution between $\mathrm{pH} 8.0$ and 12.0. The $\mathrm{pH}$ range studied in the present work is between 3.0 and 7.0, and hence, $\mathrm{Co}$ (II) presence predominates largely in this $\mathrm{pH}$ range (Marešová et al. 2011). They have also described the speciation diagram of $\mathrm{Co}(\mathrm{II})$.

The effect of $\mathrm{pH}$ on metal ion biosorption can also be studied in terms of PZC which was found to be 4.45 and 6.89, for RLP and ALP, respectively. PZC of ALP is higher than RLP as a result of saponification of protein and other organic matter increasing the carboxyl content. If the $\mathrm{pH}$ of a metal ion solution is greater than $\mathrm{pH}_{\mathrm{PZC}}$, then metal ion adsorption increases due to the availability of more functional groups such as carboxyl and hydroxyl on the adsorbent. At $\mathrm{pH}<\mathrm{pH}_{\mathrm{PZC}}$, the major metal species are positively charged. Therefore, uptake of metals is $\mathrm{M}_{1}^{\mathrm{n}+}$ $\mathrm{M}_{2}^{\mathrm{m}+}\left(\mathrm{M}_{1}^{\mathrm{n}+}=\mathrm{Na}^{+}\right.$present on the adsorbent surface; $\mathrm{M}_{2}^{\mathrm{m}+}=\mathrm{Co}^{2+}$ ) exchange process ( $\mathrm{Li}$ et al. 2008; Thirumavalavan et al. 2010).

The approach of metal cations to the surface of biosorbent is limited at lower $\mathrm{pH}$ as a result of repulsion by the biosorbent ligands strongly associated with hydronium ions $\left(\mathrm{H}_{3} \mathrm{O}^{+}\right)$(Aksu 2001). At acidic $\mathrm{pH}(\mathrm{pH}$ 3.0), the protonation of the functional groups such as carboxyl and hydroxyl results in decrease in the adsorption capacity (Fig. 3a). As $\mathrm{pH}$ increases, deprotonation of functional groups takes place and the negative charge density on the surface increases resulting in enhanced biosorption. Another possible explanation is that with increasing $\mathrm{pH}$, solubility of many metal ions decreases, and therefore, the degree of hydration of a metal ion reduces (i.e., less energy is required for removal or reorientation of water molecules associated in hydration with a metal ion). Similar results were obtained in the case of PFB1 by Suhasini et al. (1999).

\section{Effect of biomass dosage}

The adsorption was found to increase with the amount of biosorbent, since the number of active sites available for adsorption increase. With increase in the ALP dosage from 1 to $2 \mathrm{~g} / \mathrm{L}$, the adsorption capacity decreased only slightly from 26.52 to $25.17 \mathrm{mg} / \mathrm{g}$, but the adsorption almost doubled from 26.52 to $54.36 \%$ (Fig. 3b). Further increase in the biomass dose led to decreased adsorption capacity with increase in $\%$ adsorption. The decrease in adsorption capacity may be attributed to the reduction in available surface area due to agglomeration of biosorbent particles at higher dose of biosorbent as well as the combined effect of various factors such as electrostatic interactions, insufficient accessibility of solute, hindrance among binding sites, and lesser mixing (Gupta and Rastogi 2009). Hence, 2 g/L adsorbent was taken as the optimum. 
(a)

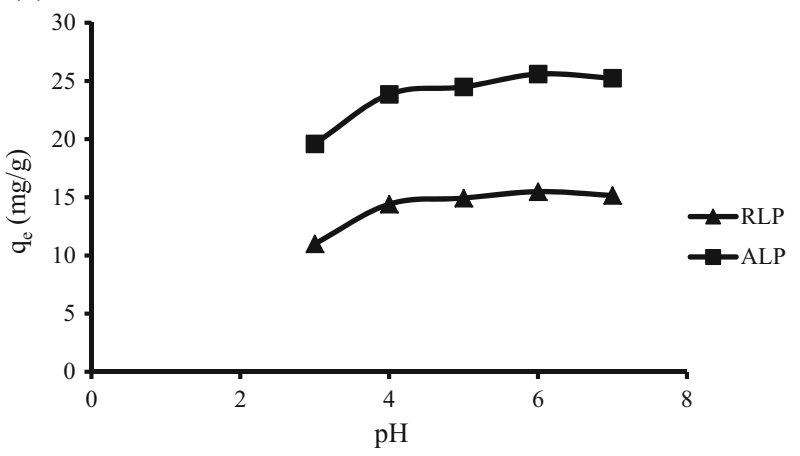

(b)

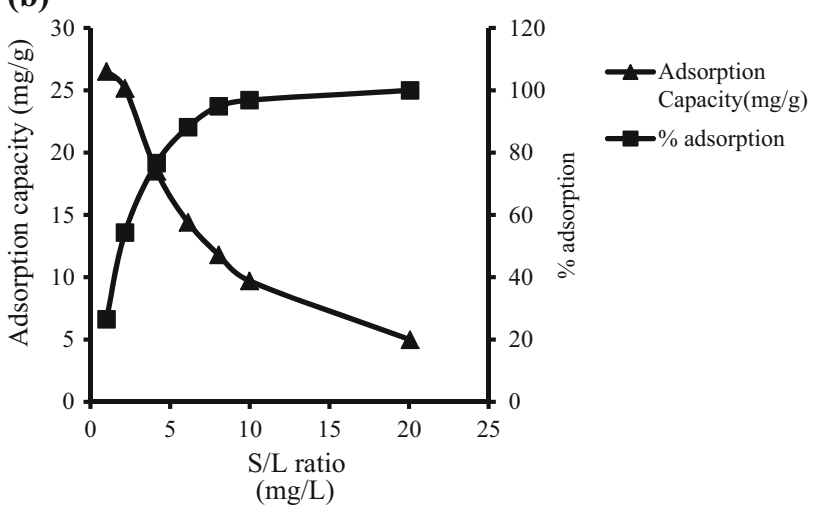

Fig. 3 a Effect of $\mathrm{pH}$ (biosorbent dose $=2 \mathrm{~g} / \mathrm{L}, C_{\mathrm{o}}=100 \mathrm{mg} / \mathrm{L}$, shaking speed $=150 \mathrm{rpm}$, contact time $=6 \mathrm{~h}$, temperature $=$ $\left.30{ }^{\circ} \mathrm{C}\right)$. b Effect of biosorbent dose $\left(C_{\mathrm{o}}=100 \mathrm{mg} / \mathrm{L}, \mathrm{pH}=6\right.$, shaking speed $=150 \mathrm{rpm}, C_{\mathrm{o}}=100 \mathrm{mg} / \mathrm{L}$, contact time $=6 \mathrm{~h}$, temperature $=30{ }^{\circ} \mathrm{C}$ )

\section{Effect of contact time}

Contact time significantly influences the biosorption efficiency. S 4 shows that the equilibrium for $\mathrm{Co}(\mathrm{II})$ uptake was achieved in $150 \mathrm{~min}$ in case of RLP and $210 \mathrm{~min}$ for ALP. In the beginning, all the sites on the surface are available and the solute concentration gradient is reasonably high. Subsequently, with the increase in contact time, the amount of cobalt ion uptake decreases, as a result of decrease in the number of available vacant sites on the surface of RLP and ALP. These results are similar to those reported by Dahiya et al. (2008). The plot of metal uptake versus time shows smooth curve resulting into saturation, signifying probable monolayer coverage of metal ions on the biosorbent surface (S 4).

\section{Effect of temperature}

The increase in temperature from 30 to $40{ }^{\circ} \mathrm{C}$ decreased the adsorption capacity of RLP and ALP by 13.29 and $5.76 \%$, respectively, and thereafter, it remained nearly constant till (a)
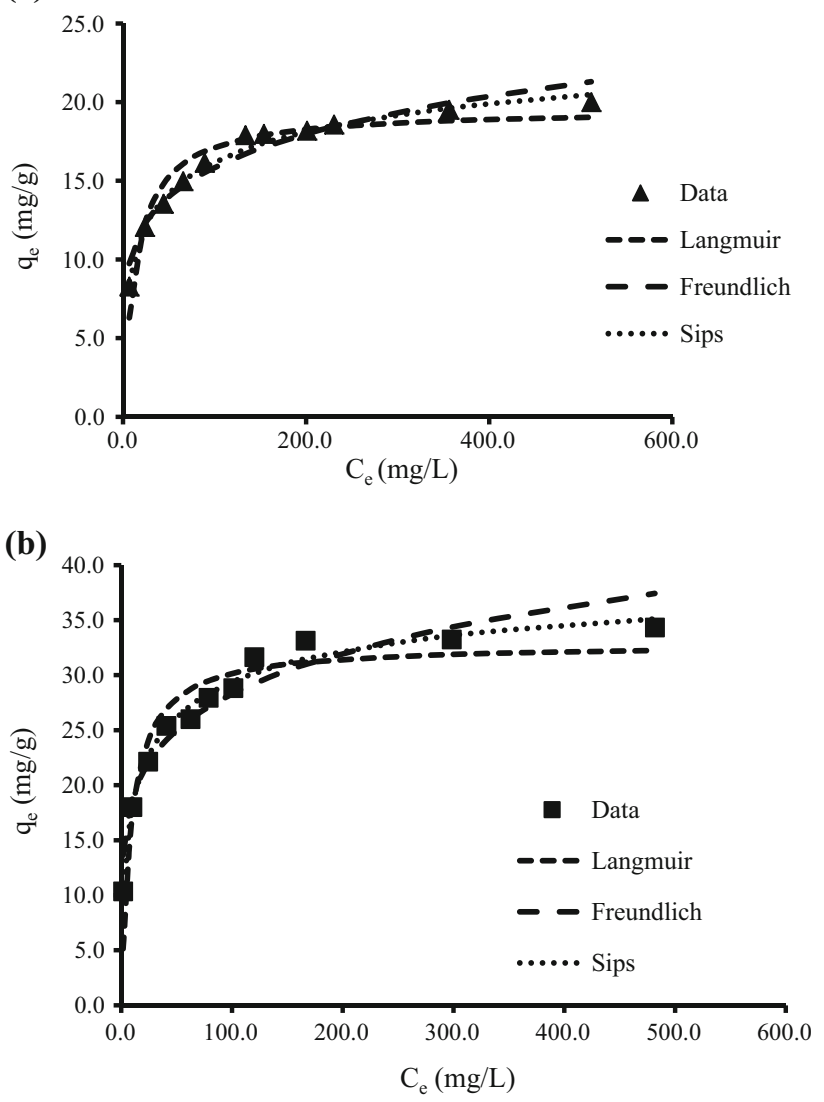

Fig. 4 Nonlinearized Langmuir, Freundlich and Sips isotherm for sorption of Co(II) ions on a RLP and b ALP (biosorbent dose $=2 \mathrm{~g}$ / $\mathrm{L}, \quad \mathrm{pH}=6, \quad$ shaking speed $=150 \mathrm{rpm}, \quad$ contact time $=6 \mathrm{~h}$, temperature $=30^{\circ} \mathrm{C}$ )

$60{ }^{\circ} \mathrm{C}$ (S 5). Thus, the adsorption of $\mathrm{Co}(\mathrm{II})$ is an exothermic process. As per the adsorption theory, desorption of adsorbed molecules from the surface of substrate takes place with increase in temperature, resulting in decrease in the adsorption (Zubair et al. 2008). Aksu (2001) also observed the same for adsorption of $\mathrm{Cd}(\mathrm{II})$ on $C$. vulgaris.

\section{Isotherm studies}

Nonlinearized Langmuir, Freundlich and Sips isotherms of RLP and ALP are plotted in Fig. 4a, b, and the values of their constants and corresponding correlation coefficients are given in Table 1. As a constant amount of biomass $(0.1 \mathrm{~g})$ was added to the solution, the number of binding sites was constant. With increase in the Co(II) concentration, $q_{\mathrm{e}}$ increased till the biomass saturated and no further sites were available for adsorption. As a result, biosorption was initially rapid but slowed down progressively as more and more sites got occupied. The equilibrium data obtained 
Table 1 Equilibrium isotherm parameters for biosorption of Co(II) on RLP and ALP

\begin{tabular}{|c|c|c|c|c|}
\hline & \multicolumn{2}{|l|}{ Linear } & \multicolumn{2}{|c|}{ Nonlinear } \\
\hline & RLP & ALP & RLP & ALP \\
\hline \multicolumn{5}{|l|}{ Langmuir } \\
\hline$q_{\max }(\mathrm{mg} / \mathrm{g})$ & 20.83 & 35.71 & 19.58 & 32.85 \\
\hline$b(\mathrm{~L} / \mathrm{mg})$ & 0.047 & 0.068 & 0.070 & 0.111 \\
\hline$r^{2}$ & 0.998 & 0.998 & 0.980 & 0.980 \\
\hline$R_{\mathrm{L}}$ & 0.037 & 0.026 & 0.025 & 0.016 \\
\hline MSE & 1.20 & 2.81 & 2.41 & 3.72 \\
\hline \multicolumn{5}{|l|}{ Freundlich } \\
\hline$K_{\mathrm{f}}$ & 6.15 & 8.87 & 6.89 & 12.45 \\
\hline$n$ & 4.90 & 4.67 & 5.53 & 5.61 \\
\hline$r^{2}$ & 0.955 & 0.985 & 0.959 & 0.978 \\
\hline MSE & 3.42 & 4.92 & 3.71 & 4.29 \\
\hline \multicolumn{5}{|l|}{ Sips } \\
\hline$k_{\mathrm{s}}(\mathrm{L} / \mathrm{g})$ & & & 5.60 & 10.31 \\
\hline$n_{\mathrm{s}}$ & & & 0.416 & 0.484 \\
\hline$a_{\mathrm{s}}(\mathrm{L} / \mathrm{mg})$ & & & 0.199 & 0.243 \\
\hline$r^{2}$ & & & 0.973 & 0.978 \\
\hline MSE & & & 3.12 & 3.98 \\
\hline \multicolumn{5}{|l|}{$q_{\mathrm{e}} \operatorname{expt} \cdot(\mathrm{mg} / \mathrm{g})$} \\
\hline RLP & 20.01 & & & \\
\hline ALP & 34.35 & & & \\
\hline
\end{tabular}

for the adsorption of Co(II) onto RLP and ALP were also fitted to the linear Langmuir equation. Linear plot of $C_{\mathrm{e}} / q_{\mathrm{e}}$ versus $C_{\mathrm{e}}$ gave the Langmuir adsorption maxima $\left(q_{\max }\right)$ value of 20.83 and $35.71 \mathrm{mg} / \mathrm{g}$ for RLP and ALP, respectively. Langmuir equilibrium constant $(b)$ was 0.047 and $0.068 \mathrm{~L} / \mathrm{mg}$ for RLP and ALP. $R_{\mathrm{L}}$ value between 0 and 1 proved that the Langmuir isotherm is favorable. The $q_{\max }$ value obtained from the nonlinear isotherm was 19.58 and $32.85 \mathrm{mg} / \mathrm{g}$ for RLP and ALP. Langmuir model was found to give better fit than Freundlich for both the adsorbents as indicated by the value of $r^{2}$ which are close to 1 . Also, the maximum adsorption capacity achieved from the Langmuir isotherm was equivalent to the monolayer capacity of the RLP and ALP. Higher value of $b$ for ALP as compared to RLP indicates more affinity of Co(II) for the former. This was confirmed during desorption studies where less amount of Co(II) was desorbed from ALP as compared to RLP. Alkali treatment converts carboxylic acid groups into $\mathrm{Na}$ carboxylates, which have better affinity and binding capacity. Concentration range up to $600 \mathrm{mg} / \mathrm{L}$ was selected to achieve the saturation of the biosorbent.

In case of Freundlich isotherm, $K_{\mathrm{f}}$ value increased from 6.15 to 8.87 on modification of peels, clearly indicating higher adsorption capacity of ALP. The value of $n$ in case of both linear and nonlinear forms of Freundlich isotherm was found to be $1<n<10$ indicating favorable adsorption. Sips model provides better correlation of the equilibrium data, since it involves three fitting parameters. The values of Sips constant, which is a measure of affinity for RLP and ALP, were 5.60 and 10.31, respectively, confirming higher affinity of ALP.

Thus, the adsorption of Co(II) on lemon peels followed Langmuir isotherm, which is in confirmation to earlier reports (Suhasini et al. 1999; Manohar et al. 2006; Parab et al. 2006; Bhatnagar et al. 2010). The $q_{\max }$ values calculated for RLP and ALP using Langmuir isotherm are comparable with the earlier reported adsorbents (Yavuz et al. 2003; Parab et al. 2006; Dahiya et al. 2008; Ahmadpour et al. 2009; Bhatnagar et al. 2010; Din et al. 2013; Koduru et al. 2014) (Table 2). However, it may be noted that comparison is possible only in terms of adsorption capacity and not from the point of view of economics as it depends on many factors such as seasonal and local availability of the biosorbent, abundance, other possible utilization modes, cost of collection and utilization, and durability of functional (adsorption, in this case) properties on aging.

\section{Kinetic Study}

The adsorption of metal ion normally occurs in two phases, initial rapid phase followed by a slow one. Initial rapid phase is due to the presence of higher concentration gradient and availability of large number of unoccupied sites, both of which reduce in the second phase gradually leading to decrease in the rate of adsorption. The values of constants and correlation coefficients obtained in case of different kinetic models are given in Table 3.

The correlation coefficient values for the pseudosecondorder plot were close to unity for both RLP and ALP indicating that the adsorption process followed pseudosecond-order equation. The calculated $q_{\mathrm{e}}$ values are close to the actual values of pseudosecond-order model (Table 3). Co(II) adsorption follows pseudosecond-order fitting (Fig. 5a), and this has been established by many researchers (Suhasini et al. 1999; Manohar et al. 2006; Bhatnagar et al. 2010).

Weber Morris model (Fig. 5b) did not give a straight line passing through the origin, indicating that intraparticle diffusion was not the only rate determining step. The graph shows three portions: the initial linear portion due to the rapid external surface adsorption of solute on available binding sites of the sorbent; the next linear part due to gradual adsorption where intraparticle diffusion is the rate controlling step; and in the third part, due to very low 


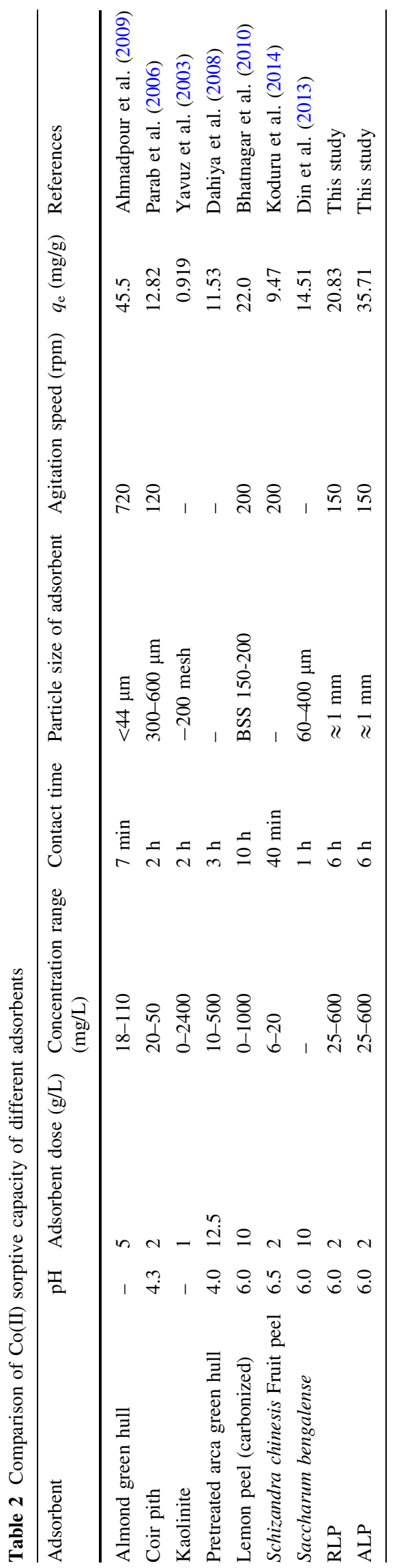

Table 3 Kinetic value parameters for biosorption of Co(II) on RLP and ALP

\begin{tabular}{lcc}
\hline & RLP & ALP \\
\hline Pseudofirst order & & \\
$q_{\mathrm{e}}(\mathrm{mg} / \mathrm{g})$ & 5.68 & 14.13 \\
$K_{1}\left(\times 10^{-3}\right)(1 / \mathrm{min})$ & 13.82 & 9.21 \\
$r^{2}$ & 0.674 & 0.827 \\
Pseudosecond order & & \\
$q_{\mathrm{e}}(\mathrm{mg} / \mathrm{g})$ & 16.129 & 26.810 \\
$K_{2}\left(\times 10^{-3}\right)(\mathrm{g} / \mathrm{mg} \min )$ & 4.136 & 1.556 \\
$h=k_{2} q_{\mathrm{e}}^{2}(\mathrm{mg} / \mathrm{g}$ min $)$ & 1.076 & 1.118 \\
$r^{2}$ & 0.998 & 0.995 \\
Intraparticle diffusion & & \\
$K_{\mathrm{i}}\left(\mathrm{mg} / \mathrm{g} \mathrm{h}{ }^{1 / 2}\right)$ & 7.603 & 11.62 \\
$r^{2}$ & 0.999 & 0.997 \\
$q_{\mathrm{e}, \text { expt }}(\mathrm{mg} / \mathrm{g})$ & 15.40 & 25.56 \\
\hline
\end{tabular}

(a)
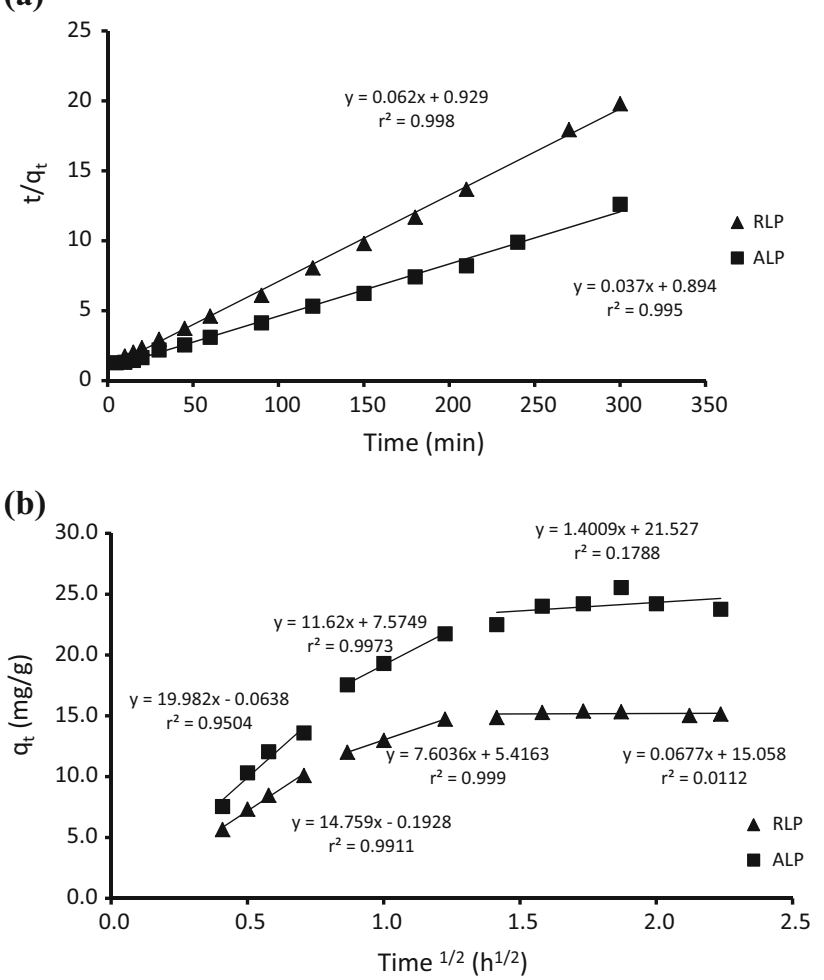

Fig. 5 a Pseudosecond order b Intraparticle diffusion model, for the adsorption of Co(II) ions on RLP and ALP (biosorbent dose $=2 \mathrm{~g} / \mathrm{L}$, $C_{\mathrm{o}}=100 \mathrm{mg} / \mathrm{L}, \mathrm{pH}=6$, shaking speed $=150 \mathrm{rpm}$, temperature $=$ $\left.30{ }^{\circ} \mathrm{C}\right)$

adsorbate concentrations in the solution, the intraparticle diffusion starts to slow down leading to equilibrium as shown by the plateau region (Ghasemi et al. 2014). 


\section{Effect of competing ions}

Industrial wastewater generally contains cations $\left(\mathrm{Na}^{+}\right.$, $\left.\mathrm{K}^{+}, \mathrm{Ca}^{2+}, \mathrm{Mg}^{2+}\right)$ and anions $\left(\mathrm{Cl}^{-}, \mathrm{SO}_{4}{ }^{2-}, \mathrm{NO}_{3}{ }^{-}\right)$along with heavy metal ions. The adsorption of heavy metal ions on the biosorbent decreases if other ions are present in the solution as they will compete with the metal ion for the sorption site. To study the influence of such ions, the experiments were performed under the optimized conditions in the presence of above-mentioned cations and anions. No significant effect on adsorption capacity of biosorbent was observed in case of cations at $50 \mathrm{mg} /$ $\mathrm{L}$, but at $100 \mathrm{mg} / \mathrm{L}$ addition, the adsorption capacity decreased by 7.92 and $14.22 \%$ due to the presence of $\mathrm{Ca}^{2+}$ and $\mathrm{Mg}^{2+}$, respectively. The presence of $\mathrm{Na}^{+}$and $\mathrm{K}^{+}$ions did not have any effect on the adsorption capacity. The presence of anions at $50 \mathrm{mg} / \mathrm{L}$ as well as $100 \mathrm{mg} / \mathrm{L}$ did not show any inhibiting effect on the biosorption. The control experiments were also carried out under the optimized conditions without the addition of other ions (S 6).The increasing ionic strength has a great influence on the activity coefficient of cobalt ions, inhibiting their transport to the sorbent surface. $\mathrm{CaCl}_{2}$ and $\mathrm{MgCl}_{2}$ have more ionic strength than similar concentrations of $\mathrm{NaCl}$ and $\mathrm{KCl}$. As a result, the adsorption capacity in the presence of $\mathrm{Ca}^{2+}$ and $\mathrm{Mg}^{2+}$ decreases indicating the influence of competitive adsorption (Han et al. 2006).

\section{Desorption and recyclability study}

During desorption, the biosorbent acts as an ion exchanger, exchanging $\mathrm{Co}(\mathrm{II})$ with $\mathrm{H}^{+}$ions from the eluting acid. Dilute $\mathrm{HCl}(0.1 \mathrm{~N})$ was found to be effective eluting agent for desorption of metal ions without affecting sorption capacity or damaging the physical structure of adsorbent in the successive cycles (S 7). Table 4 shows the adsorption and desorption efficiencies of RLP and ALP from a solution of $100 \mathrm{mg} / \mathrm{L} \mathrm{Co(II).}$ Desorption was almost complete for both the sorbents. RLP and ALP were then subjected to adsorption-desorption cycles with an intermediate regeneration step with $0.01 \mathrm{~N} \mathrm{NaOH}$. It was observed that (Table 4) the adsorption efficiency was retained only when the materials after desorption were subjected to intermediate regeneration step, in the absence of which decrease in the adsorption efficiency was observed.

Thus, Co(II) ions showed $27.62 \%$ adsorption on RLP and $56.87 \%$ on ALP which decreased to $17.68 \%$ and $38.51 \%$ for RLP and ALP, respectively, when it was subjected only to washing with water after desorption. However, with regeneration, the readsorption values were successively $26.27,27.18$ and $26.29 \%$ for RLP and 55.48, 


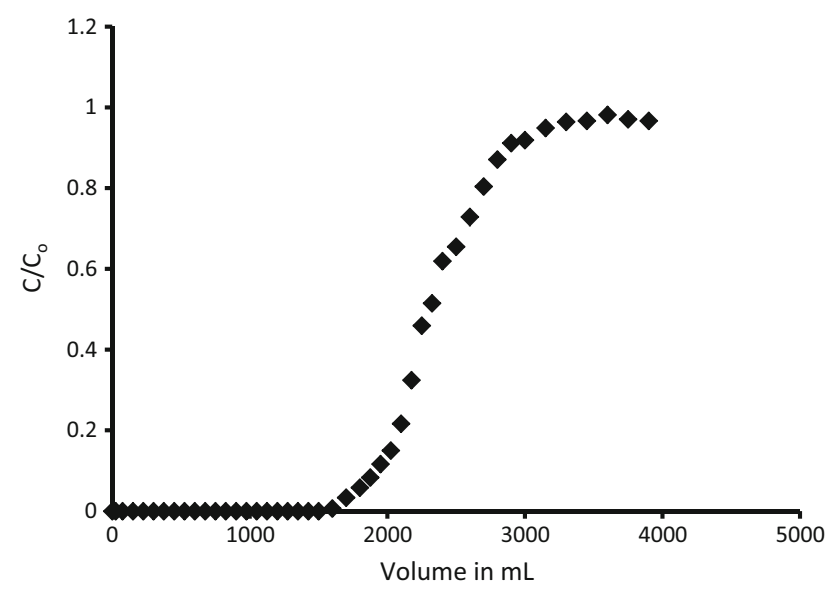

Fig. 6 Treatment of synthetic wastewater (biosorbent dose $=5 \mathrm{~g}$, $\mathrm{pH}=6$, flow rate $=5 \mathrm{~mL} / \mathrm{min}$, temperature $=30^{\circ} \mathrm{C}$ )

56.23 and $56.67 \%$ for ALP after each of the three adsorption desorption-regeneration cycles indicating nearly the same adsorption as that of the original material. No weight loss in the biomass was observed during this process confirming that no additional leaching takes place in the filtrate.

The $\mathrm{pH}$ after adsorption significantly decreased (Table 4) when the desorbed materials without regeneration were subjected to adsorption for the second time. This difference was due to the replacement of $\mathrm{H}^{+}$ions by the metal ions from the materials, which causes a decrease in $\mathrm{pH}$ of the starting bath. However, not much difference was observed in the adsorption capacity between $\mathrm{pH} 4.0$ and 7.0. Regeneration of desorbed material released $\mathrm{Na}^{+}$ into the solution during adsorption, since the modification was carried out in alkaline medium resulting in the formation of sodium salt of respective acidic groups. The difference in $\mathrm{pH}$ before and after adsorption was found to be minimal in the case of ALP when it was used in the first adsorption cycle. Hence, a loading with $\mathrm{Na}^{+}$is necessary after desorption and washing to maintain the material's original adsorption capacity.

\section{Evidence of ion exchange process}

Both metal ion and biosorbent are charged species causing electrostatic attraction; however, ion exchange predominates due to stronger bonding forces. The energydispersive X-ray spectroscopy (EDX) analysis clearly showed the involvement of ion exchange process in the metal ion adsorption. The characteristic cobalt peaks are present in the metal-loaded ALP (S 8b) which were absent in the ALP (S 8a). Once the adsorption of cobalt ions takes place on the ALP, the peaks due to $\mathrm{Na}^{+}, \mathrm{Mg}^{2+}, \mathrm{K}^{+}$and $\mathrm{Ca}^{2+}$ which were present in ALP disappear confirming involvement of the ion exchange process (Iqbal et al.
2009). The ion exchange process was further confirmed by the desorption study of metal-loaded ALP, during which more than $96 \%$ of the metal ions were liberated in the acidic media $(0.1 \mathrm{~N} \mathrm{HCl})$ due to the exchange of metal ions with $\mathrm{H}^{+}$ions in desorption process. Iqbal et al. (2009), Suryavanshi and Shukla (2010) have suggested similar ion exchange mechanism in case of other biosorbents. The ion exchange mechanism between $\mathrm{Na}^{+}$of the ALP and the $\mathrm{Co}(\mathrm{II})$ follows the reaction:

$\mathrm{Lemon}_{-}^{-}{ }_{\mathrm{COONa}}^{\mathrm{COONa}}+\mathrm{Co}(\mathrm{II}) \longrightarrow \mathrm{Lemon}_{-}-\mathrm{COO}_{\mathrm{CO}}{ }^{-} \mathrm{Co}+2 \mathrm{Na}^{+}$

\section{Treatment of synthetic wastewater}

The high adsorption capacity of the ALP obtained in the batch study can be effectively utilized for the removal of cobalt ions from the wastewater using packed columns. The synthetic wastewater was passed at $5 \mathrm{~mL} / \mathrm{min}$ flow rate through a glass column $(17 \mathrm{~cm}$ length and $1.5 \mathrm{~cm}$ internal diameter) packed with $5 \mathrm{~g}$ of ALP on glass wool support. From the breakthrough curve (Fig. 6), it is clear that $1600 \mathrm{~mL}$ of wastewater could be treated effectively by $5 \mathrm{~g}$ ALP (i.e., $320 \mathrm{~L}$ of wastewater using $1 \mathrm{~kg}$ of biosorbent). Bhatnagar et al. (2010) have shown that using one kilogram of lemon peel-activated carbon, $210 \mathrm{~L}$ of synthetic wastewater can be treated which is $34.38 \%$ less than the ALP. Thus, ALP has a potential of wastewater treatment and extensive studies in this direction are in progress.

\section{Conclusion}

ALP was found to be effective for the adsorptive separation of cobalt ions from solution owing to its high adsorption capacity mainly on carboxyl groups. Almost complete desorption of the Co(II) ions from RLP and ALP as well as the EDX spectra before and after Co(II) adsorption confirmed that the process involved was an ion exchange. The adsorption capacity increased with increase in $\mathrm{pH}$ up to 6.0, beyond which it remained constant till $\mathrm{pH} 7.0$ and thereafter precipitation of Co hydroxide started. The FTIR spectrum clearly showed the modification of functional groups and enhancement in the intensity of peaks. The increase in adsorption capacity of ALP has been explained by the increase in the number of grooves seen in SEM image of ALP. The adsorption followed Langmuir isotherm and pseudosecond-order kinetic model. One kilogram of ALP could successfully treat $320 \mathrm{~L}$ of synthetic wastewater containing various competing ions. 
Acknowledgments The authors gratefully acknowledge funding from University Grants Commission, New Delhi, under letter No. F.540/21/CAS/2007(SAP-1) dated December 10, 2007.

Conflict of interest The authors declare that they have no conflict of interest.

\section{References}

Ahmadpour A, Tahmasbi M, Bastami TR, Besharati JA (2009) Rapid removal of cobalt ion from aqueous solutions by almond green hull. J Hazard Mater 166:925-930

Aksu Z (2001) Equilibrium and Kinetic modelling of cadmium(II) biosorption by $C$. vulgaris in a batch system: effect of temperature. Sep Purif Technol 21:285-294

Andrews CM, Oberg AG (1963) Cellulose swelling by propanal-2retention. Text Res J 33:330-332

Awadalla FT, Pesic B (1992) Biosorption of cobalt with the AMT ${ }^{\mathrm{TM}}$ metal removing agent. Hydrometallurgy 28:65-80

Bhatnagar A, Minocha AK, Sillanpää M (2010) Adsorptive removal of cobalt from aqueous solution by utilizing lemon peel as biosorbent. Biochem Eng J 48:181-186

Dahiya S, Tripathi RM, Hegde AG (2008) Biosorption of heavy metals and radionuclide from aqueous solutions by pre-treated arca green hull biomass. J Hazard Mater 150:376-386

Din MI, Mirza ML, Ata S, Athar M, Mohsin IU (2013) Thermodynamics of biosorption for removal of $\mathrm{Co}$ (II) Ions by an efficient and ecofriendly biosorbent (Saccharum bengalense): kinetics and isotherm modeling. J Chem 2013:1-11

Ekmekyapar F, Aslan A, Bayhan YK, Cakici A (2012) Biosorption of $\mathrm{Pb}$ (II) by nonliving lichen biomass of Cladonia rangiformis Hoffm. Int J Environ Res 6:417-424

Freundlich HMF (1906) Uber die adsorption in losungen. Z Phys Chem 57(A):385-470

Ghasemi M, Ghasemi N, Zahedi G, Alwi SRW, Goodarzi M, Javadian H (2014) Kinetic and equilibrium study of $\mathrm{Ni}(\mathrm{II})$ sorption from aqueous solutions onto Peganumharmala-L. Int $\mathbf{J}$ Environ Sci Technol 11:1835-1844

Gupta VK, Rastogi A (2009) Biosorption of hexavalent chromium by raw and acid-treated green alga Oedogonium hatei from aqueous solutions. J Hazard Mater 163:396-402

Han R, Li H, Li Y, Zhang J, Xiao H, Shi J (2006) Biosorption of copper and lead ions by waste beer yeast. J Hazard Mater B137:1569-1576

Hlihor RM, Diaconu M, Fertu D, Chelaru C, Sandu I, Tavares T, Gavrilescu M (2013) Bioremediation of $\mathrm{Cr}(\mathrm{VI})$ polluted wastewaters by sorption on heat inactivated Saccharomyces cerevisiae biomass. Int J Environ Res 7:581-594

Ho YS, Wang CC (2004) Pseudo-isotherms for the sorption of cadmium ion onto tree fern. Process Biochem 39:761-765

Ileri O, Cay S, Uyanik A, Erduran N (2014) Removal of common heavy metals from aqueous solutions by waste Salvadora persica L. branches (Miswak). Int J Environ Res 8:987-996

Iqbal M, Saeed A, Zafar SI (2009) FTIR spectrophotometry, kinetics and adsorption isotherms modeling, ion exchange, and EDX analysis for understanding the mechanism of $\mathrm{Cd}^{(2+)}$ and $\mathrm{Pb}^{(2+)}$ removal by mango peel waste. J Hazard Mater 164:161-171

Koduru JR, Chang YY, Kim IS (2014) Low-cost Schizandra chinesis fruit peel for $\mathrm{Co}$ (II) removal from aqueous environment: adsorption properties and mechanism. Asian J Chem 26:289-297
Lagergren S (1898) Zur theorie der sogenannten adsorption gelöster stoffe. Kungliga Svenska Vetenskapsakademiens. Handlingar Band 24:1-39

Langmuir I (1918) The adsorption of gases on plane surfaces of glass, mica and platinum. J Am Chem Soc 40:1361-1403

Leyva-Ramos R, Bernal-Jacome LA, Acosta-Rodriguez I (2005) Adsorption of cadmium(II) from aqueous solution on natural and oxidized corncob. Sep Purif Technol 45:41-49

Li X, Tang Y, Cao X, Lu D, Luo F, Shao W (2008) Preparation and evaluation of orange peel cellulose adsorbents for effective removal of cadmium, zinc, cobalt and nickel. Colloid Surf A-Physicochem Eng Asp 317:512-521

Manohar DM, Noeline BF, Anirudhan TS (2006) Adsorption performance of Al-pillared bentonite clay for the removal of cobalt(II) from aqueous phase. Appl Clay Sci 31:194-206

Marešová J, Pipíška M, Rozložník M, Horník M, Remenárová L, Augustín J (2011) Cobalt and strontium sorption by moss biosorbent: modeling of single and binary metal systems. Desalination 266:134-141

O'Connell DW, Birkinshaw C, O'Dwyer TF (2008) Heavy metal adsorbents prepared from the modification of cellulose: a review. Bioresour Technol 99:6709-6724

Pai RS, Shukla SR (2005a) Removal of $\mathrm{Pb}$ (II) from solution using cellulose-containing materials. J Chem Technol Biotechnol 80:176-183

Pai RS, Shukla SR (2005b) Adsorption of $\mathrm{Cu}(\mathrm{II}), \mathrm{Ni}$ (II) and $\mathrm{Zn}$ (II) on modified jute fibres. Bioresour Technol 96:1430-1438

Parab H, Joshi S, Shenoy N, Lali A, Sarma US, Sudersanan M (2006) Determination of kinetic and equilibrium parameters of the batch adsorption of $\mathrm{Co}(\mathrm{II}), \mathrm{Cr}(\mathrm{III})$ and $\mathrm{Ni}(\mathrm{II})$ onto coir pith. Process Biochem 41:609-615

Rouhollahi F, Zamani A, Karimi K, Etesami N (2014) Enhancement of nickel biosorption on fungal biomass by enzymatic and alkali pretreatments. Int J Environ Sci Technol 11:1911-1918

Sharma RK, Wooten JB, Baliga VL, Lin X, Chan WG, Hajaligol MR (2004) Characterization of chars from pyrolysis of lignin. Fuel 83:1469-1482

Shukla PM, Shukla SR (2013) Biosorption of Cu(II), Pb(II), Ni(II), and $\mathrm{Fe}(\mathrm{II})$ on alkali treated coir fibers. Sep Sci Technol 48:421-428

Singh J, Ali A, Prakash V (2014) Removal of lead (II) from synthetic and batteries wastewater using agricultural residues in batch/column mode. Int J Environ Sci Technol 11:1759-1770

Sips R (1948) On the structure of a catalyst surface. J Chem Phys 16:490-495

Suhasini IP, Sriram G, Asolekar SR, Sureshkumar GK (1999) Biosorptive removal and recovery of cobalt from aqueous systems. Process Biochem 34:239-247

Suryavanshi US, Shukla SR (2009) Adsorption of Ga(III) on oxidized coir. Ind Eng Chem Res 48:870-876

Suryavanshi U, Shukla SR (2010) Adsorption of $\mathrm{Pb}^{2+}$ by alkalitreated citrus limetta peels. Ind Eng Chem Res 49:11682-11688

The environmental management (water quality standards) regulations (2007) First schedule, Permissible limits for municipal and industrial effluents, 20

Thirumavalavan M, Lai YL, Lin LC, Lee JF (2010) Cellulose-based native and surface modified fruit peels for the adsorption of heavy metal ions from aqueous solution: langmuir adsorption isotherms. J Chem Eng Data 55:1186-1192

Thirumavalavan M, Lai YL, Lee JF (2011) Fourier transform infrared spectroscopic analysis of fruit peels before and after the adsorption of heavy metal ions from aqueous solution. J Chem Eng Data 56:2249-2255 
Weber WJJ, Morris JC (1963) Kinetics of adsorption on carbon from solution. J Sanit Eng Div Proc Am Soc Civ Eng 89:31-60

Yavuz O, Altunkaynak YC, Guzel F (2003) Removal of copper, nickel, cobalt and manganese from aqueous solution by kaolinite. Water Res 37:948-952
Zubair A, Bhatti HN, Hanif MA, Shafqat F (2008) Kinetic and equilibrium modeling for $\mathrm{Cr}(\mathrm{III})$ and $\mathrm{Cr}(\mathrm{VI})$ removal from aqueous solutions by Citrus reticulata waste biomass. Water Air Soil Pollut 191:305-318 